\title{
Identificação de indivíduos vulneráveis no entorno de um hospital universitário: conectando vulnerabilidade, solidariedade e saúde
}

\author{
Identification of vulnerable individuals \\ in the area surrounding a university hospital: \\ connecting vulnerability, solidarity and healthcare
}

Hellen Cristina Sthal ${ }^{1}$

Heloisa Wey Berti ${ }^{1}$
${ }^{1}$ Departamento de Enfermagem, Faculdade de Medicina de Botucatu, Universidade Estadual Paulista. Distrito de Rubião Júnior s/n. 18618-970 Botucatu SP.

hellen_sthal@hotmail.com

\begin{abstract}
In the area around a university hospital in the interior of São Paulo state people are found sleeping, eating or resting on the lawns and surrounding areas, and they linger in such sites for hours. This study sought to identify and characterize vulnerable individuals in the area around the hospital by offering help. Data were collected from November 2007 to October 2008, on a weekly basis and on randomly selected days and times. The people found in these places were identified, and 52 subjects were interviewed. The individuals were, predominantly, females (67.3\%), white (51.9\%), married (59.6\%), had attended school for up to four years $(44.2 \%)$ and did not have a defined profession (84.6\%). Most of them were waiting for bus transportation provided by their hometown administration; the mean waiting time was approximately 90 minutes and most of the subjects had certain needs during the waiting period. Help was offered to 15 individuals who reported specific needs at the moment of the interview. It was concluded that these individuals were in a situation of individual, social and systematic vulnerability, especially in terms of socio-economic vulnerability. They showed reduced self-determination ability and submitted themselves to unfavorable conditions due to their dependence on public services.
\end{abstract}

Key words Nursing, Vulnerability, Reception
Resumo No entorno de um hospital universitário do interior do estado de São Paulo há pessoas dormindo, se alimentando ou descansando nos gramados e arredores, permanecendo nestes locais durante horas. Este estudo objetivou identificar e caracterizar indivíduos vulneráveis em área externa deste hospital, oferecendo ajuda. A coleta dos dados foi realizada no período de novembro de 2007 a outubro de 2008, semanalmente, em dias e horários sorteados. Identificaram-se pessoas que permaneciam nesses locais, sendo entrevistados 52 sujeitos. Esses indivíduos são, predominantemente, do sexo feminino (67,3\%), brancos (51,9\%), casados (59,6\%), com escolaridade de até quatro anos de estudo (44,2\%) e sem profissão definida (84,6\%). A maioria aguardava o horário do ônibus da prefeitura de seu município de origem; o tempo médio de espera foi de aproximadamente 90 minutos e grande parte dos sujeitos apresentou necessidades durante os períodos de espera. Foi oferecida ajuda a 15 pessoas que referiram necessidades no momento da entrevista. Concluiu-se que esses indivíduos se encontram em situação de vulnerabilidade individual, social e programática, destacando-se a vulnerabilidade sócio-econômica, apresentam capacidade de autodeterminação reduzida, submetendo-se a condições desfavoráveis por dependerem dos serviços públicos.

Palavras-chave Enfermagem, Vulnerabilidade, Acolhimento 


\section{Introdução}

\section{Da percepção do problema aos questionamentos: delimitando uma discussão}

O Hospital Universitário (HU) abordado neste estudo é um hospital-referência, de nível terciário, com capacidade atual de 477 leitos. Abrange uma população de aproximadamente três milhões de habitantes ${ }^{1}$.

Como estudante de enfermagem da Faculdade que agrega este hospital, percebi que, quase sempre, há pessoas dormindo, se alimentando, ou descansando nos gramados e arredores próximos às áreas de internação no entorno do hospital, sendo que algumas dessas pessoas permanecem nesses locais por várias horas ao longo do dia. Essa situação chamou minha atenção, incitando questionamentos como: quem são essas pessoas? Por que e por quanto tempo elas permanecem nesses locais que me parecem tão desconfortáveis? Será que estão precisando de alguma ajuda? Esses indivíduos permanecem no entorno de uma instituição pública de saúde, onde se encontram profissionais e estudantes da área. Num contexto em que tanto se tem falado em humanização da assistência à saúde, será que as atitudes voltadas a essas pessoas, que parecem tão expostas, têm sido solidárias e humanas?

O inconformismo diante da situação e a inquietude gerada por esses questionamentos levaram-me à elaboração deste estudo, fundamentado nos conceitos de vulnerabilidade e solidariedade em saúde.

\section{Vulnerabilidade e solidariedade: revisando conceitos}

A palavra vulnerabilidade deriva do latim vulnerare $=$ ferir, vulnerabilis $=$ que causa lesã $0^{2}$. Dessa forma, o indivíduo vulnerável é aquele que pode ser ferido, afetado de forma negativa, prejudicado ${ }^{2,3}$.

No cenário da saúde, o conceito de vulnerabilidade é relativamente recente, emergindo na década de 80 como sendo uma possibilidade de se interpretar a epidemia da AIDS ${ }^{4}$. A formação do conceito nessa área está relacionada ao "esforço de superação das práticas preventivas apoiadas no conceito de risco"s.

Ayres et al. ${ }^{6}$ apontam um modelo de vulnerabilidade em saúde constituído por três componentes interligados: o individual (comportamento pessoal), o social (contexto social) e o progra- mático ou institucional (programas de combate à doença, no caso a AIDS). De acordo com os autores, a vulnerabilidade individual se refere à quantidade e à qualidade de informação de que os indivíduos dispõem sobre saúde e a capacidade de colocar em prática essa informação, transformando-a em atitudes protetoras. O componente social da vulnerabilidade diz respeito ao acesso à informação, ao acesso a recursos cognitivos e materiais, a instituições sociais como escola e serviços de saúde, envolvendo também o poder de influenciar decisões políticas e a possibilidade de transpor barreiras culturais. Já o componente programático da vulnerabilidade se refere ao grau e à qualidade de compromisso, recursos e monitoramento de programas de prevenção e cuidado voltados ao controle de enfermidades.

Esse conceito de vulnerabilidade supera a característica individualizadora e probabilística do conceito de risco, abrangendo aspectos coletivos e do contexto e levando em conta a disponibilidade ou não de recursos que possam proteger os indivíduos.

No cenário da bioética, o conceito de vulnerabilidade ganhou importância nos últimos anos, principalmente a partir da década de noventa ${ }^{2}$. Esse conceito, segundo Von Zuben ${ }^{3}$, evoca duas categorias da condição humana: finitude (condição de mortal) e transcendência (capacidade de superar o estado de fragilidade), relacionando-se com princípios da bioética como autonomia, dignidade e integridade; sendo que os princípios de dignidade, integridade e vulnerabilidade foram consagrados na Declaração Universal sobre Bioética e os Direitos do Homem, da Unesco, em 2005, complementando os princípios clássicos já consagrados pelo Relatório Belmont (1978): autonomia, beneficência e justiça.

Por herança histórica e cultural, sempre se pensou que os vulneráveis fossem os deficientes físicos e/ou mentais, as crianças, os senis e os institucionalizados de qualquer ordem, mas essa visão não engloba as pessoas que se encontram em outras situações de vulnerabilidade, como por exemplo, as populações pobres, que padecem de vulnerabilidade socioeconômica. Dessa maneira, pessoas vulneráveis são todas aquelas que, por quaisquer razões, tenham sua capacidade de autodeterminação reduzida e que não possuem capacidade, total ou parcial, para proteger seus interesses ${ }^{2}$.

Guimarães et al. ${ }^{7}$ defendem a ideia de que a vulnerabilidade e a redução da autonomia são fenômenos que podem ou não estar interligados. De acordo com as autoras, a autonomia é 
um conceito ético que diz respeito à pessoa enquanto indivíduo e a vulnerabilidade é um conceito que pressupõe o estabelecimento de relações de desigualdade entre pessoas ou grupos, seja por motivos sociais, econômicos, políticos, de saúde ou outros. Assim, os sujeitos vulneráveis, quando são maiores de idade e não possuem condições que os impeçam de decidir, possuem os requisitos para serem considerados autônomos. No entanto, são, às vezes, incapazes de decidir livremente ou de manifestar sua decisão porque fatores sociais, políticos, econômicos, ou outros, dificultam ou impedem que esses sujeitos o façam.

Alguns estudos ${ }^{8-10}$ têm problematizado a vulnerabilidade socioeconômica de uma grande parcela da população como sendo um dos condicionadores da precarização do atendimento aos seus direitos, inclusive aos direitos de saúde. Os altos índices de desigualdade social e econômica afetam as condições de sobrevivência da família pobre, forçando-a a aceitar e a se submeter aos serviços públicos existentes, mesmo que sejam precários e ineficientes. No contexto da assistência à saúde isto reflete a alienação "consentida" do usuário que, ao ser destituído do poder de decisão sobre a própria saúde, perde a autonomia para decidir sobre o que lhe seja melhor.

"No contexto do dia-a-dia, é difícil imaginar um consentimento informado para um paciente autônomo, quando falta a esse paciente o primeiro de seus direitos, o de escolher o que melhor lhe convier para tratar de seus males. Impossibilitado, se vê também constrangido a se sujeitar à rotina no atendimento que, raras vezes, é seguida com a preocupação de verificar suas dificuldades. Nada resta senão concordar com o que lhe é oferecido"11.

Para mudar essa situação é preciso que os profissionais criem relações mais horizontais e solidárias com os usuários dos serviços de saú$\mathrm{de}^{3,9,12,13}$. Segundo Bellato et al. ${ }^{9}$, é necessário ter um "olhar ético" na relação entre o profissional de saúde e o usuário do serviço, ou seja, um olhar "que parte de um ser humano co-responsável, que tem na empatia e solidariedade para com o outro momentaneamente fragilizado, o balizamento para suas ações profissionais”.

A solidariedade é o ato de sair de si mesmo e contemplar o outro em sua condição humana, de apresentar um gesto acolhedor ${ }^{14}$. Selli et al. ${ }^{15}$ propõem a solidariedade como instrumentoguia na prática voluntária e como valor a ser incorporado na agenda bioética do século XXI. A importância das redes solidárias não está só na mobilização e distribuição de recursos para pessoas carentes, mas também na disseminação de uma ideia de cidadania e de interdependência entre os membros da sociedade ${ }^{15,16}$. Na área da saúde, as associações solidárias podem ser de grande importância para melhorar as condições de saúde e romper o isolamento individual. O indivíduo enfermo sente-se, muitas vezes, limitado e tende a reduzir as iniciativas de trocas com seus contatos pessoais, isolando-se. Neste caso, a disponibilidade de apoio solidário pode aumentar a auto-estima do indivíduo doente, contribuindo com o sucesso do tratamento ${ }^{16}$.

Dessa forma, ainda há muito que se fazer para se consolidar um Sistema Público de Saúde onde a solidariedade não seja apenas um conceito teórico, e sim um instrumento na prática profissional. Considerando-se a vulnerabilidade e os direitos do usuário do serviço público de saúde, pode-se pensar em mudanças para que a assistência à saúde seja mais qualitativa e humana ${ }^{9,17}$. Assim, justifica-se a realização deste estudo que tem por objetivo identificar e caracterizar, entre usuários do serviço público de saúde, indivíduos em situação de vulnerabilidade e as necessidades apresentadas por eles nessas situações, procurando formas de intervenção solidária.

\section{Método}

Trata-se de um estudo transversal, prospectivo, realizado no período de novembro de 2007 a outubro de 2008. Durante este período, uma vez por semana, em dias e horários sorteados, percorreu-se o entorno das áreas de internação do Hospital Universitário em questão, observando pessoas que se encontravam comendo, dormindo ou descansando nos gramados ou em outros locais próximos. O sorteio dos dias da semana e horários foi feito sem repetição, visando à cobertura de todos os dias da semana e horários diurnos. Foram incluídos no sorteio os sete dias da semana e três diferentes períodos: [manhã (08$12 \mathrm{~h})$; tarde (12-16h) e vespertino (16-19h)]. Foram entrevistadas 52 pessoas, num universo estatístico, estimado para o período do estudo, de 1290 pessoas. Dessa forma, a amostra analisada neste estudo corresponde a aproximadamente $4 \%$ do universo estimado.

Os indivíduos foram devidamente informados sobre os objetivos da pesquisa e só foram entrevistados após a assinatura do Termo de Consentimento Livre e Esclarecido. Durante a entrevista avaliou-se a vulnerabilidade e o tipo 
de necessidade apresentada pelo entrevistado, oferecendo ajuda, quando necessário. Segundo Minayo $^{18}$, a entrevista é a técnica mais utilizada no processo de trabalho de campo, sendo um instrumento privilegiado de coleta de dados devido à possibilidade de a fala revelar sistemas de valores individuais, condições estruturais e, ao mesmo tempo, poder transmitir as representações de determinados grupos, em condições sócio-econômicas e culturais específicas.

Estruturalmente, a entrevista pode ser de vários tipos, sendo que neste estudo optou-se pela entrevista semi-estruturada, que combina perguntas fechadas (estruturadas) e abertas, onde o entrevistado pode discorrer sobre o tema proposto.

Goode et. al. ${ }^{19}$ lembram que a entrevista não é simplesmente um meio para a coleta de informações, mas sim uma situação de interação social que pode ser profundamente afetada pela relação entre os atores, colocados em posição de desigualdade. Neste estudo atentou-se para a condução cuidadosa da entrevista, especialmente pela situação de vulnerabilidade dos indivíduos entrevistados.

Com relação ao tratamento dos depoimentos, utilizou-se o modelo operacional sugerido por Minayo $^{18}$. A partir dos dados colhidos, procedeu-se à reflexão acerca dos conceitos iniciais, e o material escrito foi cuidadosamente organizado e analisado. Para isto foram adotados alguns passos: $1^{\circ}$. Organização dos dados, incluindo releitura do material, organização dos depoimentos em determinada ordem e organização dos dados de observação; $2^{\circ}$. Classificação dos dados através de leitura exaustiva, constituindo um "Corpus" de comunicações e categorias empíricas; $3^{\circ}$. Análise final, buscando-se a significação do contexto sócio-econômico-cultural por meio da análise compreensiva das falas dos indivíduos entrevistados. Isto possibilitou o "encontro da especificidade do objeto com a realidade vivida"18.

\section{Resultados}

A maioria dos entrevistados é do sexo feminino $(67,3 \%)$ e pertence à faixa etária de 20 a 39 anos $(44,2 \%)$, sendo que a média de idade da amostra é de 41,1 anos (desvio padrão de 14,84). Os sujeitos são predominantemente brancos $(51,9 \%)$, casados $(59,6 \%)$, com escolaridade de até quatro anos de estudo (44,2\%) e um filho (34,6\%), conforme consta na Tabela 1. A média do número de anos de estudo é de 5,4 anos (desvio pa- drão de 3,26) e a média do número de filhos é de 2,2 (desvio padrão de 1,92).

Poucos indivíduos relataram ter uma profissão definida $(15,4 \%)$, enquanto a maioria $(84,6 \%)$ referiu ter uma ocupação atual; $46,2 \%$ da amostra foi composta por donas-de-casa. Nenhum dos entrevistados é morador da cidade em que se localiza o hospital, mas todos eram provenientes de cidades do estado de São Paulo.

Quanto ao motivo da vinda ao hospital no dia da entrevista, a maioria dos entrevistados $(59,5 \%)$ veio acompanhar outra pessoa (filho menor de idade, pais, sobrinhos, irmãos mais novos, entre outros) em consulta ou exame médico de nível ambulatorial (consultas ou exames agendados previamente); os demais vieram para

Tabela 1. Caracterização sócio-demográfica da amostra, com relação a sexo, idade, cor, estado civil, escolaridade e número de filhos.

\begin{tabular}{|c|c|c|}
\hline Característica & $\begin{array}{c}\mathrm{No}^{\circ} \mathrm{de} \\
\text { pessoas }\end{array}$ & $\%$ \\
\hline \multicolumn{3}{|l|}{ Sexo } \\
\hline Feminino & 35 & $67,3 \%$ \\
\hline Masculino & 17 & $32,7 \%$ \\
\hline \multicolumn{3}{|l|}{ Idade } \\
\hline Até 19 anos & 02 & $3,8 \%$ \\
\hline De 20 a 39 anos & 23 & $44,2 \%$ \\
\hline De 40 a 59 anos & 20 & $38,5 \%$ \\
\hline 60 anos ou mais & 07 & $13,5 \%$ \\
\hline \multicolumn{3}{|l|}{ Cor } \\
\hline Branco & 27 & $51,9 \%$ \\
\hline Pardo & 22 & $42,3 \%$ \\
\hline Negro & 03 & $5,8 \%$ \\
\hline \multicolumn{3}{|l|}{ Estado civil } \\
\hline Casado & 31 & $59,6 \%$ \\
\hline Solteiro & 05 & $9,6 \%$ \\
\hline Divorciado & 04 & $7,7 \%$ \\
\hline União estável & 10 & $19,2 \%$ \\
\hline Viúvo & 02 & $3,9 \%$ \\
\hline \multicolumn{3}{|l|}{ Escolaridade } \\
\hline Analfabeto & 03 & $5,8 \%$ \\
\hline Até 4 anos de estudo & 23 & $44,2 \%$ \\
\hline De 5 a 8 anos de estudo & 16 & $30,8 \%$ \\
\hline De 9 a 11 anos de estudo & 09 & $17,3 \%$ \\
\hline Mais de 11 anos de estudo & 01 & $1,9 \%$ \\
\hline \multicolumn{3}{|l|}{ Número de filhos } \\
\hline Nenhum & 05 & $9,6 \%$ \\
\hline $\mathrm{Um}$ & 18 & $34,6 \%$ \\
\hline Dois & 12 & $23,1 \%$ \\
\hline Três & 09 & $17,3 \%$ \\
\hline Quatro & 03 & $5,8 \%$ \\
\hline Cinco ou mais & 05 & $9,6 \%$ \\
\hline Total & 52 & $100 \%$ \\
\hline
\end{tabular}


consulta própria ou exame médico $(38,5 \%)$ ou para visitar alguém internado no hospital (2\%) (Figura 1).

Dentre os entrevistados, $82,7 \%$ se encontravam sentados ou deitados no gramado aguardando o horário do ônibus da prefeitura de sua cidade para ir embora. Os demais estavam aguardando o horário da consulta médica/exame $(15,3 \%)$ ou o horário de visitas das enfermarias (2\%) (Figura 2).

A média do tempo de espera no local em questão foi de 89,13 minutos (desvio padrão de 60,95), ou seja, aproximadamente 1 hora e 30 minutos de espera. A maioria das pessoas (80,7\%) aguardou no local por um período de tempo compreendido entre 15 minutos e 2 horas. Contudo, algumas pessoas chegaram a permanecer nos arredores das áreas de internação do hospital por até quatro horas seguidas, conforme exposto na Tabela 2.

Com relação ao período de permanência, foram entrevistadas 13 pessoas $(25 \%)$ no período da manhã (08-12h); 37 (71,2\%) no período da tarde (12-16h) e $2(3,8 \%)$ no período vespertino (16-17h), sendo que a faixa de horário na qual há maior incidência de indivíduos aguardando nos arredores das áreas de internação é das 10 às 16:00 horas, principalmente entre 12 e 15 horas.

Quando inquiridos sobre o motivo de permanecerem naquele local e não em outro, grande parte dos indivíduos respondeu que não encontrou outro lugar melhor para esperar. Disseram que, embora o gramado não seja um lugar confortável e adequado para se aguardar por um longo período de tempo, pelo menos há sombra e eles podem deitar e descansar, já que os bancos

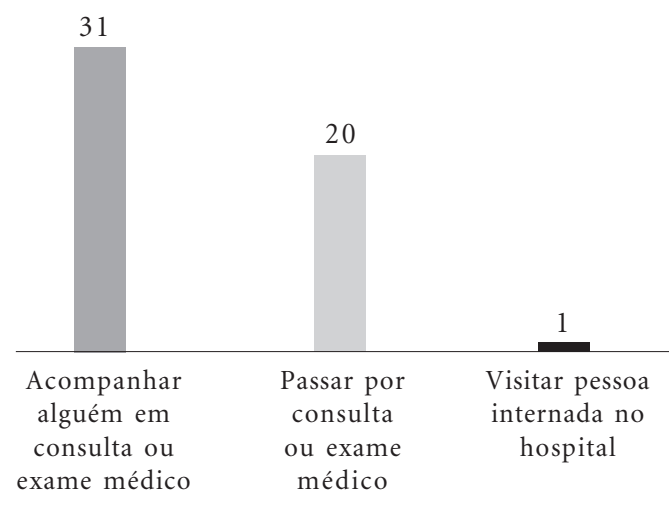

Figura 1. Número de pessoas em relação ao motivo da vinda ao hospital no dia da entrevista. destinados à espera, próximos aos ambulatórios, estão sempre lotados e nem todos ficam na sombra, como mostra alguns trechos retirados de falas dos entrevistados: "Resolvi ficar aqui porque os bancos na sombra, perto dos ambulatórios estavam cheios e nos outros estava batendo sol. Pelo menos aqui na grama, debaixo da árvore, tem sombra e sossego"; "Pra te falar bem a verdade, fico aqui por falta de opção"; “Aqui é mais fresco, tem árvores e tem mais espaço para a neném brincar" (referindo-se à filha, de um ano de idade); "A barriga pesa muito e as costas doem, então a gente tem necessidade de descansar, né? Pelo menos aqui no gramado é certeza que tem lugar para sentar e até deitar se a gente quiser" (fala de uma gestante, no último trimestre da gravidez, que aguardava já há 1 hora sentada no gramado).

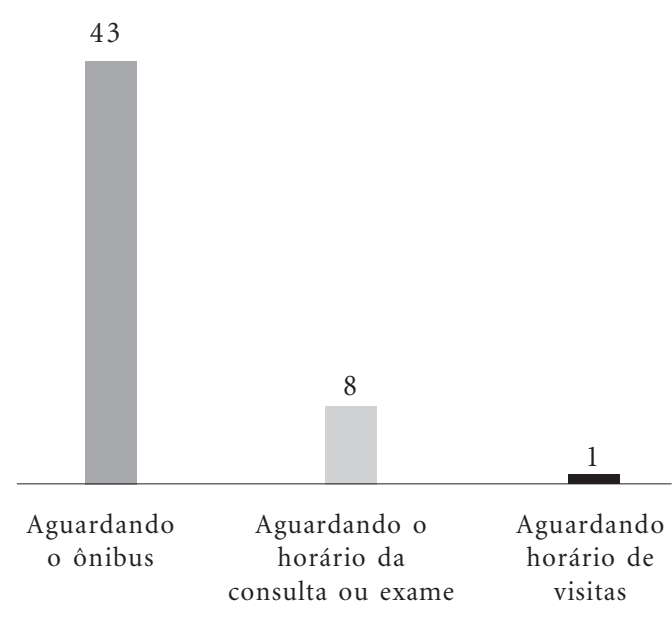

Figura 2. Número de pessoas em relação ao motivo da permanência nos arredores das áreas de internação do hospital.

Tabela 2. Tempo de espera nos arredores das áreas de internação do hospital.

\begin{tabular}{lcr}
\hline \multicolumn{1}{c}{ Tempo de espera } & $\begin{array}{c}\text { No de } \\
\text { pessoas }\end{array}$ & $\%$ \\
\hline Até 30 minutos & 14 & $26,99 \%$ \\
31 minutos a 1 hora & 14 & $26,99 \%$ \\
1 hora e 1 minuto a 2 horas & 14 & $26,99 \%$ \\
2 horas e 1 minuto a 3 horas & 07 & $13,59 \%$ \\
3 horas e 1 minuto a 4 horas & 03 & $5,8 \%$ \\
Mais de 4 horas & 0 & \\
Total & $\mathbf{5 2}$ & $\mathbf{1 0 0} \%$ \\
\hline
\end{tabular}


Dentre os 52 indivíduos entrevistados, cinco $(9,6 \%)$ referiram que se tratava da primeira vez que eles aguardavam nesse local (entorno do hospital). As outras 47 pessoas entrevistadas $(90,4 \%)$ relataram que já haviam aguardado outras vezes nesse local. Dessas 47 pessoas, 39 $(83 \%)$ relataram ter apresentado alguma necessidade nas situações em que precisaram permanecer no entorno do hospital, conforme mostra a Figura 3.

Os depoimentos dos entrevistados demonstraram as seguintes necessidades: falta de banheiros e bebedouros limpos e mais próximos, falta de conforto e de distração na espera e falta de um local apropriado para comer e para trocar os bebês, conforme exposto nestes trechos de falas: "Os banheiros e os bebedouros ficam longe e estão sempre sujos. Às vezes os banheiros ficam trancados também"; "O gramado é sujo, cheio de lixo e tem muita formiga"; "Falta conforto para a gente poder descansar enquanto espera”; "É muito ruim ficar aqui nos dias frios, e quando chove a gente tem que sair correndo procurar outro lugar"; "Não tem um lugar decente para a gente comer, então a gente acaba comendo sentada aqui na grama mesmo, mas eu me sinto muito incomodada de ter que comer aqui, com um monte de gente passando e olhando"; "Os banheiros não têm lugar apropriado para trocar fralda de bebê e muitas vezes não têm nem papel higiênico".

As outras oito pessoas (17\%) que também já tiveram que aguardar mais de uma vez nesse lo-

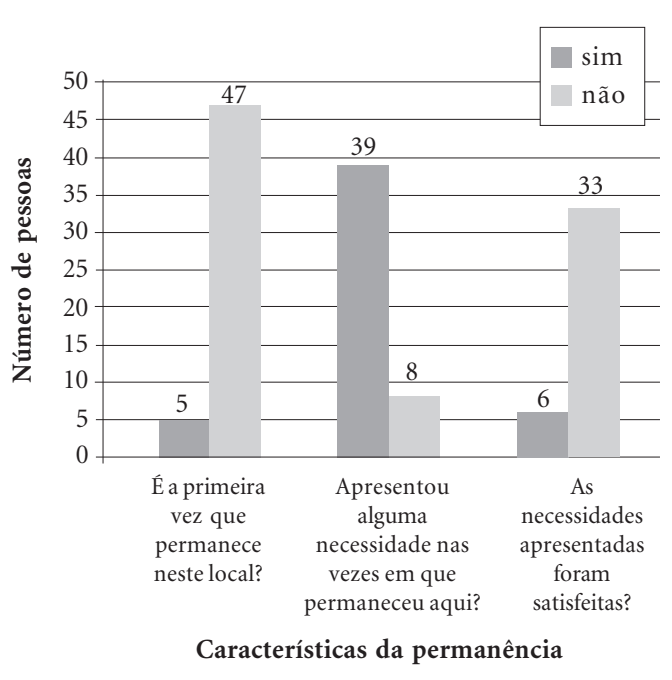

Figura 3. Número de pessoas em relação a características da permanência no entorno do hospital. cal disseram não ter apresentado nenhuma necessidade, pronunciando justificativas como: "Sempre fui muito bem atendido aqui e não posso reclamar de nada, muito menos de esperar na grama"; "Já sou acostumado, a falta de conforto não me incomoda"; "Não acho eu que tenha apresentado nenhuma necessidade, já passei por coisa muito pior do que ter que esperar na grama. Além do que, é melhor ser atendido em hospital bom como este e ter que esperar na grama do que ser atendido em um hospital ruim que tem uma sala de espera maravilhosa”.

Dentre os 39 sujeitos que referiram ter apresentado alguma necessidade, cinco $(12,8 \%)$ disseram que essas necessidades foram atendidas através de iniciativas pessoais, como trazer garrafa térmica com água de casa, trazer lençois e cobertas para forrar a grama e torná-la menos desconfortável, trazer revistas, jogos ou realizar qualquer outra atividade de distração. As outras 34 pessoas $(87,2 \%)$ relataram que as necessidades apresentadas não foram atendidas (Figura 3).

Todas as 52 pessoas participantes do estudo foram indagadas sobre a existência de alguma necessidade no momento da entrevista, sendo que 15 indivíduos $(28,8 \%)$ referiram apresentar alguma necessidade naquele momento. Os demais $37(71,2 \%)$ negaram apresentar qualquer necessidade naquele instante, sendo que vários deles relataram ter apresentado necessidades quando começaram a frequentar o hospital, mas que agora já estão adaptados: “depois de tanto tempo, já acostumei com o desconforto e já aprendi a me virar sozinho".

Foi oferecida ajuda aos 15 indivíduos que referiram alguma necessidade, sendo que quatro deles $(26,6 \%)$ aceitaram a ajuda. As ajudas oferecidas incluíram mostrar outros lugares onde as pessoas poderiam aguardar, caso desejassem (na tentativa de oferecer um pouco mais de conforto); fornecer informações em geral; mostrar a localização de banheiros, bebedouros, restaurante, lanchonetes, ambulatórios, enfermarias, Pronto Socorro ou qualquer outro local onde a pessoa precisasse ir e não soubesse como.

As 11 ajudas recusadas foram todas referentes a mostrar à pessoa a localização de outros lugares onde ela poderia aguardar e outros banheiros e bebedouros que ela poderia usar, caso desejasse. Os indivíduos justificaram a recusa dizendo que já conheciam essas alternativas, mas, na opinião deles, não eram melhores do que as que eles estavam utilizando, então, mesmo apresentando alguma necessidade, preferiam continuar ali. As ajudas aceitas foram referentes a in- 
formações sobre os locais disponíveis para a compra de alimentos no campus; mostrar à pessoa 0 banheiro mais próximo; levar a pessoa até a área de espera próxima aos ambulatórios (local coberto e com bancos).

De forma geral, as ajudas prestadas foram bem sucedidas, buscando-se soluções para as dificuldades encontradas, na tentativa de atender ao máximo à necessidade apresentada pelo indivíduo. Os entrevistados se mostraram dispostos, receptivos e gratos pela iniciativa solidária, embora nem todos a tenham aceitado. Vários sujeitos surpreenderam-se com a iniciativa, explicando que ninguém nunca havia parado para perguntar se eles precisavam de alguma coisa, em nenhuma das diversas vezes que eles aguardaram o dia todo no campus da faculdade.

\section{Discussão}

Todos os entrevistados eram provenientes de outras cidades, vieram para o Hospital Universitário no ônibus da prefeitura de sua cidade (gratuito) e dependiam dele para voltar à cidade de origem. Os ônibus das diferentes cidades chegam ao HU às $7 \mathrm{~h}$ trazendo todas as pessoas que têm alguma atividade a ser realizada no hospital naquele dia. Dependendo da distância entre a cidade de origem e Botucatu, as pessoas chegam a sair de suas cidades às $02 \mathrm{~h}$ da madrugada para estar no HU às 7h. Esses ônibus só retornam às cidades de origem depois que todos os pacientes foram atendidos, o que geralmente ocorre por volta das $16 \mathrm{~h}$ ou 17h. Esse dado talvez possa justificar o fato de a maioria das entrevistas terem sido realizadas entre 10 e 16h, período em que muitas das pessoas já foram atendidas e aguardam o ônibus de volta para a sua cidade. No período vespertino (16-19h), os ônibus geralmente já estão partindo, então as pessoas se deslocam para locais mais próximos ao estacionamento dos ônibus, abandonando o entorno do hospital, o que explica a redução do número de entrevistados nesse período.

O serviço ambulatorial deste hospital atende de segunda a sexta-feira, das 07 às $17 \mathrm{~h}$, o que provavelmente justifica o fato de não terem sido encontradas pessoas aguardando nos arredores do HU, em nenhum dos períodos, nos dias de sábado, domingo e feriados. A maioria dos sujeitos veio ao hospital para acompanhar parentes ou amigos que passariam por consulta ou exame médico. Como essas pessoas aguardam no campus praticamente o dia todo, perdem o dia de trabalho, caso trabalhem. Então as famí- lias tendem a solicitar que as pessoas que não trabalham fora de casa venham acompanhar o familiar ou amigo que tem consulta ou exame marcado no HU e necessita de acompanhante. Esse fato, relatado por alguns entrevistados, talvez possa explicar o grande número de mulheres donas-de-casa encontrado nesse estudo.

As áreas próximas às unidades de internação do HU, local onde os indivíduos em questão permanecem, compreendem uma região extensa, composta principalmente por áreas de gramado, que constituem caminho para as pessoas que frequentam o campus se locomoverem dentro do mesmo. Esses locais são todos a céu aberto, contendo algumas árvores. Devido ao intenso fluxo de pessoas que passam ou permanecem nesses locais, o gramado geralmente apresentase sujo, evidenciando o lixo que é jogado no chão.

Algumas pessoas trazem de casa lençóis, edredons ou cobertores que estendem no gramado para se deitar; no entanto, encontram-se pessoas deitadas diretamente na grama, muitas vezes dormindo. Encontram-se também pessoas se alimentando nesses locais, sentadas na grama e, não raro, próximas ao lixo resultante das refeições de outras pessoas. Nem todos os locais dessa área possuem banheiro e bebedouro próximos; muitas vezes os banheiros destinados a esses pacientes se encontram trancados ou extremamente sujos, impossibilitando o uso. Os bancos se restringem à área de espera próxima aos ambulatórios e alguns deles se localizam em área onde não há sombra. No gramado, encontramse pessoas de várias idades, desde bebês no colo das mães até pessoas bastante idosas, sujeitos esses que, apesar da condição de fragilidade, permanecem aí por várias horas.

Percebe-se, então, a situação de vulnerabilidade em que esses indivíduos se encontram. "A fragilidade não necessita ser biológica, nem tampouco o constrangimento necessita ser legalizado para que essas pessoas se encontrem em situações de vulnerabilidade"2.

Dentre os entrevistados, notaram-se vários indivíduos que padecem de vulnerabilidade socioeconômica, ou seja, falta de recursos sociais e/ ou financeiros. Há pessoas que passam o dia todo no campus da Faculdade porque realmente não possuem recursos financeiros para pagar uma passagem de ônibus rodoviário; e alguns deles não possuem dinheiro nem para se alimentar durante o período de permanência.

Os resultados aqui encontrados são condizentes com os estudos que problematizam a vulnerabilidade socioeconômica dos usuários como 
fator de precarização do atendimento de seus direitos. Grande parte dos indivíduos atendidos neste HU apresenta algum grau de carência socioeconômica, e, em sua maioria, são usuários que fazem jus ao termo "paciente", aceitando o que lhe é imposto e ampliando sua submissão ao serviço de saúde, uma vez que necessitam dele. Essas pessoas geralmente não veem o atendimento à sua saúde como um direito que possuem, assegurado por lei, mas sim como uma espécie de favor, uma vez que são atendidos gratuitamente na instituição e necessitam desse atendimento.

Verificou-se que algumas pessoas, embora também busquem pelos serviços públicos porque necessitam deles, ainda preservam o poder de voz de discordar, opinar e reivindicar, apontando os pontos precários e as necessidades apresentadas. Essas pessoas relataram que consideram inadequado e às vezes até humilhante terem que permanecer no gramado, comer e descansar num local desconfortável, onde há fluxo grande de pessoas que passam, olham e demonstram semblante de surpresa, de pena ou de quem já se acostumou com a situação.

Segundo o modelo conceitual de vulnerabilidade em saúde, sugerido por Ayres et. al. ${ }^{6}$ e já comentado aqui, os indivíduos em questão padecem tanto de vulnerabilidade individual, quanto de vulnerabilidade social e programática. Muitos dos indivíduos entrevistados carecem quantitativa e qualitativamente de informação em saúde. Socialmente, esses indivíduos também se apresentam vulneráveis, uma vez que possuem, muitas vezes, acesso limitado a recursos cognitivos e materiais, e a instituições sociais como a escola (a maioria dos entrevistados possuí escolaridade de, no máximo, quatro anos de estudo). $\mathrm{O}$ poder de participar e influenciar decisões políticas e de enfrentar barreiras culturais tende a estar bem distante da realidade desses sujeitos, eles se calam diante das situações desfavoráveis por pensar que jamais terão voz ativa na tomada de decisões, e mesmo quando reconhecem as necessidades e as verbalizam, se sentem sem força social para tomar qualquer atitude reivindicadora. Com relação ao componente programático, os indivíduos em questão carecem de ações que favoreçam seu acesso social a recursos, sua dignidade, seu poder de decisão e sua influência política e cultural, bem como ações que promovam o atendimento integral à sua saúde, incentivando sua autonomia e respeitando seus direitos.

Diante dos inúmeros obstáculos que se apresentam para a assistência à saúde no país, sejam de ordem financeira, política, organizativa ou éti- ca, coloca-se em pauta o debate sobre a questão da qualidade da atenção prestada. Atualmente discutem-se a necessidade de se humanizar o cuidado, a assistência e a relação com o usuário do serviço de saúde ${ }^{20}$.

No campo da atenção em saúde, o termo humanização tem sido utilizado com diferentes significados e entendimentos, relacionando-se com os direitos dos pacientes e a ética voltada ao respeito ao outro. Desde a década de noventa, a humanização da atenção à saúde vem sendo tratada como política pública, iniciando-se no ambiente hospitalar, e, atualmente, sendo dirigida para todos os níveis de atenção de saúde ${ }^{21}$.

A proposta da Política Nacional de Humanização (PNH) enfatiza a necessidade de assegurar atenção integral à população e estratégias de ampliar a condição de direitos e de cidadania das pessoas ${ }^{22}$. A humanização requer um processo reflexivo acerca dos valores e princípios que orientam a prática profissional, pressupondo, além de um tratamento e cuidado digno, solidário e acolhedor por parte dos profissionais da saúde, uma nova postura ética que permeie todas as atividades profissionais e processos de trabalho institucionais ${ }^{23}$.

Apesar dos recentes esforços para melhorar a qualidade dos serviços públicos de saúde no Brasil, iniquidades e violência institucional ainda persistem nos hospitais ${ }^{24}$. Os profissionais da área da saúde parecem gradativamente desumanizar-se, favorecendo a desumanização de sua prática $^{23}$. É nítida a necessidade de se elaborar e implementar ações voltadas à verdadeira humanização da assistência à saúde, promovendo a autonomia e a dignidade do usuário, respeitando-o em sua cidadania. A questão a ser discutida neste momento é o fato de que essas ações, quando são elaboradas, costumam ser direcionadas apenas à humanização do atendimento propriamente dito, ou seja, pensa-se somente em estratégias que humanizam o cuidado ao usuário a partir do momento em que ele adentra na unidade onde será atendido. A humanização na unidade de atendimento é muito importante, no entanto, as pessoas não apresentam necessidades somente no momento em que estão sendo atendidas dentro do hospital. A humanização é um conceito complexo e abrangente, que necessita de ações reformistas e de integração entre diversos setores para ser operacionalizada. Assim sendo, a humanização no atendimento à saúde deve englobar todas as etapas, incluindo o período de espera evidenciado por este trabalho.

Além dos âmbitos governamental e institucional, há outro ponto forte a ser discutido: as ins- 
tâncias individual e social. É comum aos profissionais e estudantes da área de saúde o fato de criticarem a falta de ações governamentais e institucionais voltadas à melhoria da qualidade da assistência; entretanto, passam despercebidas as "pequenas" ações individuais ou coletivas que podem fazer a diferença. Relembremos que os sujeitos deste estudo referiram que dentre todas as pessoas que passam pelo gramado enquanto eles se encontram lá (incluindo profissionais e estudantes da área da saúde), ninguém nunca parou para perguntar se eles precisavam de alguma ajuda, de alguma informação. Esse dado nos leva a refletir sobre a solidariedade em nossa sociedade atual. É até mesmo contraditório pensar que ações governamentais e institucionais possam implantar completamente a humanização no atendimento à saúde, sendo que os próprios profissionais que atuam diretamente na assistência não apresentam, muitas vezes, atitudes pessoais motivadas pela solidariedade.

Os resultados das ajudas oferecidas nessa pesquisa foram satisfatórios e, embora o número de ajudas prestadas tenha sido muito pequeno, elas fizeram a diferença para as pessoas que receberam a iniciativa solidária, mostrando que é através das "pequenas" ações que se começam a instituir a humanização e a solidariedade. Além das iniciativas individuais, a sociedade civil pode se organizar em torno de ações solidárias. Deste modo, a operacionalização da humanização da assistência à saúde depende também de mudanças pessoais, da ênfase em valores ligados à defesa da vida, da possibilidade de ampliação do grau de desalienação e de transformação do trabalho em processo criativo e prazeroso ${ }^{25}$.

\section{Considerações finais}

A realização deste estudo permitiu a identificação dos indivíduos em situação de vulnerabilidade no entorno do Hospital Universitário em questão, assim como das necessidades apresentadas por esses indivíduos nessas condições. Esses indivíduos se encontram em situação de vulnerabilidade individual, social e programática, com destaque para a vulnerabilidade sócio-econômica; apresentam sua capacidade de autodeterminação reduzida, submetendo-se a condições desfavoráveis, como a espera prolongada em local inadequado, por dependerem por completo dos serviços públicos utilizados.

Para a implementação de um cuidado humanizado é preciso valorizar a dimensão subje- tiva e social em todas as práticas de atenção e gestão, fortalecer o trabalho em equipe multiprofissional, fomentar a construção de autonomia e protagonismo dos sujeitos e valorizar os profissionais de saúde ${ }^{18}$. Contudo, também são necessárias as iniciativas pessoais, afinal, o acolhimento do usuário não é realizado pela instituição em si, mas sim pelos profissionais que atuam diretamente na assistência.

A humanização da assistência é um conceito amplo e complexo, que propõe uma atuação que leve à garantia dos direitos dos cidadãos e ao aprimoramento da vida em sociedade. Assim, a promoção do bem-estar e o atendimento às necessidades dos indivíduos durante o tempo de espera no entorno do hospital, como apresentado, também devem fazer parte das ações de humanização da assistência à saúde.

Percebe-se, que é necessária a reflexão sobre a condição de vulnerabilidade apresentada por esses sujeitos, pensando-se em ações que possam atender às necessidades apresentadas. Como algumas das soluções possíveis, foram sugeridas pela pesquisadora à direção do hospital as seguintes: construção de bancos embaixo das árvores; construção de quiosques no gramado, contendo bancos e mesas onde as pessoas poderão se sentar e realizar as refeições, caso desejem; melhor higiene do gramado, incluindo retirada mais frequente do lixo, a disponibilização de um número maior de lixeiras e também a conscientização coletiva sobre a importância de se conservar o gramado limpo; melhor higiene dos banheiros, incluindo a limpeza frequente e também a conscientização dos usuários sobre as vantagens de se conservar os banheiros limpos; manter os banheiros abertos e disponíveis para uso, a menos que haja justificativa plausível para estarem interditados; adaptar nos banheiros uma bancada adequada para os pais trocarem as fraldas dos bebês; construção de uma sala de espera na área próxima ao estacionamento dos ônibus, com banheiro e bebedouros; iniciativa por parte do HC de conversar com os gestores dos municípios que encaminham pacientes para Botucatu sobre os horários dos ônibus e sobre as condições socioeconômicas desses pacientes, na tentativa de que esses municípios colaborem para a resolução do problema.

Por fim, conclui-se que o reconhecimento e a compreensão das situações de vulnerabilidade proporcionaram uma reflexão sobre as práticas solidárias e sobre a humanização da assistência à saúde em um hospital universitário de grande porte. 
Ficou clara a importância de se aproximar da população, conhecer suas necessidades, ouvir suas opiniões e valorizar sua participação no sistema de saúde, pois é a partir dessa aproximação que se podem identificar as situações de vulnerabilidade e encontrar formas efetivas de intervenção para que as necessidades apresentadas sejam atendidas de forma solidária e humanizada, respeitando sempre a cidadania, a dignidade, a autonomia e os direitos dos sujeitos.

\section{Referências}

1. Universidade Estadual Paulista (UNESP). História da Faculdade de Medicina. [On-line] 2007 abr [acessado 2007 jun 29]. Disponível em: http://www.fmb. unesp.br/instituicao/apresent_med.php

2. Barchifontaine CP. Vulnerabilidade e dignidade humana. Mundo Saúde (1995) [periódico na Internet]. 2006 jul-set [acessado 2007 maio 2]; 30(3): [cerca de 6 p.]. Disponível em: https://www.scamilo.edu.br/ index.php?pag $=$ publi_revista\&rev $=\mathrm{s} \& a n o=2005$

3. Von Zuben NA. Vulnerabilidade e decisão: tensão no pacto médico. Mundo Saúde (1995) [periódico na Internet]. 2006 jul-set [acessado 2007 maio 4]; 30(3): [cerca de 6 p]. Disponível em: https://www.scamilo. edu.br/index.php?pag=publi_revista \&rev=s\&ano $=2005$

4. Sánchez AIM, Bertolozzi MR. Pode o conceito de vulnerabilidade apoiar a construção do conhecimento em saúde coletiva? Cien Saude Colet 2007; 12(2):319-324.

5. Meyer DEE, Mello DF, Valadão MM, Ayres JRCM. "Você aprende. A gente ensina?" Interrogando relações entre educação e saúde desde a perspectiva da vulnerabilidade. Cad Saude Publica 2006; 22(6): 1335-1342.

6. Ayres JRCM, França Júnior I, Calazans GJ, SalettiFilho HC. O conceito de vulnerabilidade e as práticas de saúde: novas perspectivas e desafios. In: Czerenia D, Freitas CM, organizadores. Promoção da saúde: conceitos, reflexões, tendências. Rio de Janeiro: Fiocruz; 2003. p. 117-139.

7. Guimarães MCS, Novaes SC. Autonomia reduzida e vulnerabilidade: liberdade de decisão, diferença e desigualdade. Bioética 1999; 7(1):21-24.

8. Gomes MA, Pereira MLD. Família em situação de vulnerabilidade social: uma questão de políticas públicas. Cien Saude Colet 2005; 10(2):357-363.

9. Bellato R, Pereira WR. Direitos e vulnerabilidade: noções a serem exploradas para uma nova abordagem ética na enfermagem. Texto Contexto Enferm 2005; 14(1):17-24.

10. Magalhães R. Monitoramento das desigualdades sociais em saúde: significados e potencialidades das fontes de informação. Cien Saude Colet 2007; 12(3): 667-673.

11. Meira AR. Bioética e vulnerabilidade: o médico e o paciente. Rev Assoc Med Bras 2004; 50(3):249-251.

\section{Colaboradores}

HC Sthal e HW Berti participaram igualmente de todas as etapas da elaboração do artigo.
12. Pettengill MAM, Angelo M. Vulnerabilidade da família: desenvolvimento do conceito. Rev Latinoam Enfermagem 2005; 13(6):982-988.

13. Costa AM. Integralidade na atenção e no cuidado a saúde. Saúde soc 2004; 13(3):5-15.

14. Tognetta LRP, Assis OZM. A construção da solidariedade na escola: as virtudes, a razão e a afetividade. Educ Pesqui [periódico na Internet]. 2006 janabr. [acessado 2007 maio 21]; 32(1):[cerca de 7p.]. Disponível em: http://www.scielo.br/scielo.php? script=sci_arttext\&pid $=$ S1517-97022006000100004\& ing $=$ pt\&nrm $=$ iso

15. Selli L, Garrafa V. Bioética, solidariedade crítica e voluntariado orgânico. Rev Saude Publica 2005; 39(3):473-478.

16. Andrade GRB, Vaitsman J. Apoio social e redes: conectando solidariedade e saúde. Cien Saude Colet 2002; 7(4):925-934.

17. Castiel LD. Insegurança, ética e comunicação em saúde pública. Rev Saude Publica 2003; 37(2):161-167.

18. Minayo MCS. O desafio do conhecimento. $8^{\text {a }}$ ed. São Paulo: Hucitec; 2004.

19. Goode WJ, Hatt PK. Métodos em pesquisa social. $4^{\mathrm{a}}$ ed. São Paulo: Companhia Editora Nacional; 1973.

20. Oliveira BRG, Collet N, Vieira CS. A humanização na assistência à saúde. Rev Latino-am Enfermagem 2006; 14(2):277-284.

21. Fortes PAC. Ética, direitos dos usuários e políticas de humanização da atenção à saúde. Saúde soc 2004; 13(3):30-35.

22. Santos-Filho SB. Perspectivas da avaliação na Política de Humanização em Saúde: aspectos conceituais e metodológicos. Cien Saude Colet 2007; 12(4):999-1010.

23. Backes DS, Lunardi VL, Lunardi Filho WD. A humanização hospitalar como expressão da ética. Rev Latino-am Enfermagem 2006; 14(1):132-135.

24. Gomes AMA, Nations MK, Luz MT. Pisada como pano de chão: experiência de violência hospitalar no nordeste brasileiro. Saúde soc 2008; 17(1):61-72.

25. Campos GWS. Humanização na saúde: um projeto em defesa da vida? Interface (Botucatu) 2005; 9(17): 398-400.

Artigo apresentado em 09/03/2009

Aprovado em 21/08/2009

Versão final apresentada em 22/09/2009 